\title{
A Two Stage Procedure Osteotomy Osteoclasis as a Safe Way of Treating Genu Valgus Deformity. A case report.
}

\author{
Asfaw Ayele \\ Consultant Orthopedic Surgeon Menilik II Hospital AddisAbaba Ethiopia, \\ Email-asfawabebe@yahoo.com. \\ https://dx.doi.org/10.4314/ecajs.v22i1.5
}

This is a case report of a fifteen years old male patient from north Shoa about one hundred and twenty $\mathrm{km}$ from the capital city of Ethiopia., who was having a knock-knee deformity since child hood. Even he didn't remember when he started to notice it. Finally about six months back one remote relative was visiting him and brought him to our Hospital where I gave him hope by telling him that is manageable and I did convince him that he will have a corrected knee within a short period of time and all families were happy. Finally patient was admitted and investigated then I did a two stage procedure (osteotomy-osteoclasis) where on immediate post-operative day it was notable the correction and after a month the cast was removed where the limb was straight.

Key words: Osteotomy, osteoclasis, genuvalgum

\section{Introduction}

Genuvalgum deformity is physiological in small children. It is normal part of development and may not cause any symptoms but when it comes to adults and bigger children it manifests as pain in the affected knee and also atypical and awkward walking is noticed. The most common location is distal femur although proximal tibia can be in some cases.in Ethiopia Most children who had had this deformity accept it as if it is a bad omen or something which happen to them due to supernatural power. Most families will not bring such children to the hospital instead they hide them behind the curtain in fear of the stigmata of disability.

\section{Case report}

This is a fifteen years old male patient from north Shoa about one hundred and twenty KM from Addis Ababa who came to our Hospital with the knock knee deformity since childhood where was investigated and assessed where he had atypical gait pattern.The positive physical finding were typical knock knee deformity and increase inter malleolar distance. For which I did two stage procedure done one after the other with interval of eight days and safely achieved the correction of deformity.

\section{Technical description}

Under general anesthesia and method of asepsis, sterile drapes applied and above knee tourniquets applied. Medial longitudinal incision done. Wound is opened layer by layer and reached bone with minimum spillage of blood. Then I did open wedge osteotomy of distal 


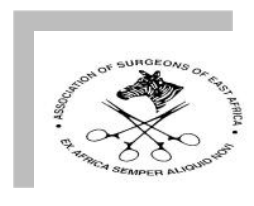

femur in a triangular fashion with open angle on the medial side and close the wound without correction of the deformity. Then I applied a long leg cast with the deformity. After a week I did castotomy in the same fashion as the operation and patient was taken to Operation Theater where under general anesthesia I did correct the deformity by closing the wedge. A week lap is taken before closing the wedge $b / c$ the hematoma will organize and the osteoblasts commences to lay down osteoid. With that complete correction achieved and the defect was casted in a correct position. That was followed by physiotherapy. There was no need to staple, to plate, to fix with foreign object. The figures below show the preoperative, immediate post-operative, and final appearances.

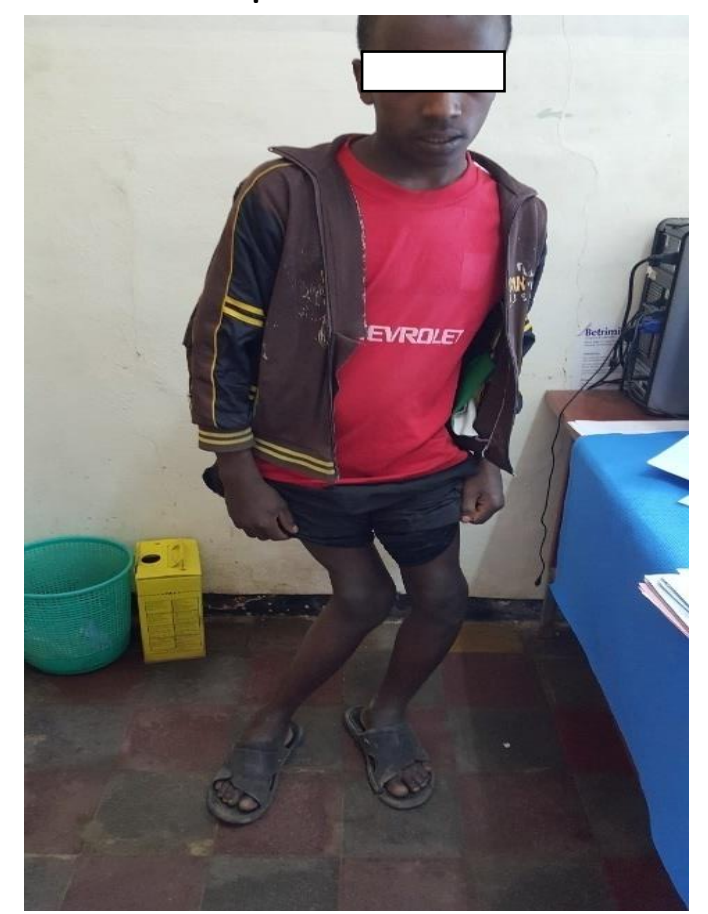

Figure 1

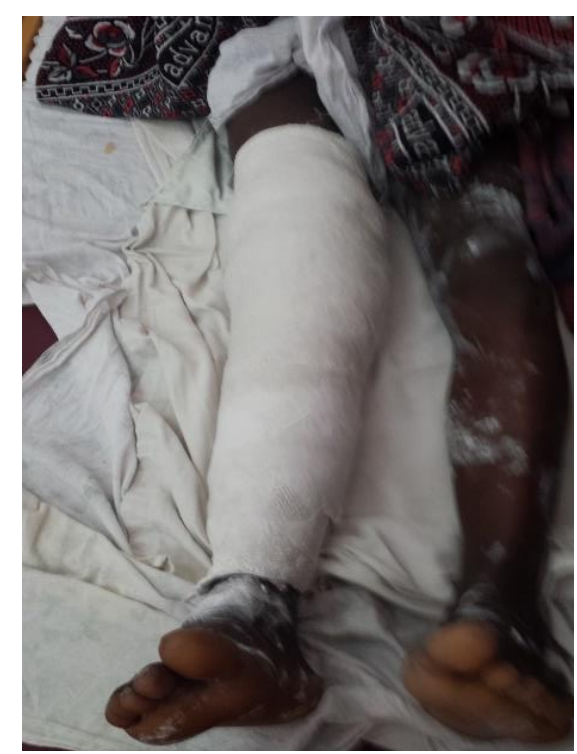

Figure 2

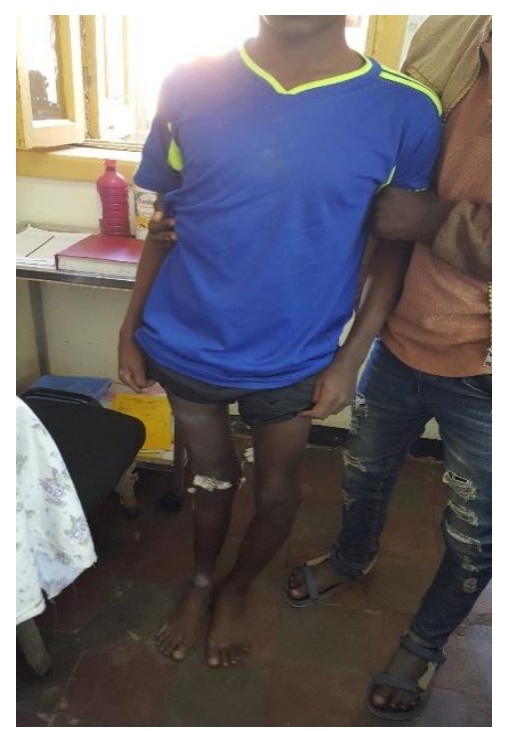

Figure 3 


\section{Discussion}

Knock knee deformities are a normal part of development, not uncommon to see in children between three and six years of age (physiologic genu valgum). At this time the anatomical angle can be as high as fifteen degree of valgus. This physiological genu valgum gradually remodels to the adult average value of five to seven degree valgus. If deformity persists to the adult age not only the mechanics of gait compromised there is also significant angular deformity and pain in the legs. If deformity persists surgical treatment is the best option of management.in our case I used a two stage procedure osteotomy-osteoclasis and the result was inspiring. Thus this procedure is safe and better way of treating genu valgus deformity in bigger children and in adult.

\section{Conclusion}

Osteotomy osteoclasis is the safest way of treating genu valgus deformity even in areas of limited resource. Health education to families of the disabled to bring their children with such deformities to the Hospital.

Reference

1. Current orthopedics diagnosis and treatment. HARRYB. SKINNER $.4^{\text {th }}$ edition

2. Campbell's operative Orthopedics twelfth edition by Mosby 2013.

3. Apley's system of Orthopedics and fractures $9^{\text {th }}$ edition pp 557.by LouisSolomon, DavidWarwick, Selvaduri Nayagam.

4. Nelson text book of pediatrics 20th edition volume II page 3263 Philadelphia pa 2016 .

5. Sherman M. physiologic valgus deformity of knee .south med journal1960 